\title{
Correction to: Comment on "Bidirectional Quantum Teleportation of Two-Qubit State Via Four-Qubit Cluster State"
}

\section{Vikram Verma ${ }^{1}$}

Published online: 3 October 2020

C) Springer Science+Business Media, LLC, part of Springer Nature 2020

\section{Correction to: Int J Theor Phys (2020) \\ https://doi.org/10.1007/s10773-020-04581-3}

The author found a mistake in his published article that somehow crept in after the author corrected proofs.

In page- 3 of the published article, the last line of the first paragraph from bottom of the page and the second paragraph from bottom of the page should be modified as shown in Table below:

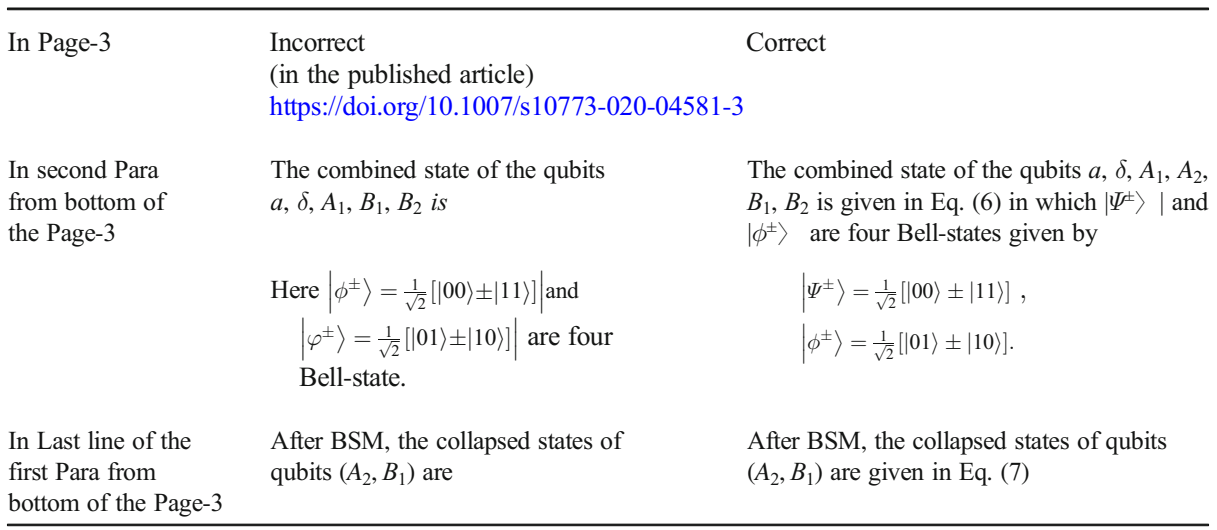

The online version of the original article can be found at https://doi.org/10.1007/s10773-020-04581-3

\author{
Vikram Verma \\ vikramverma18@gmail.com
}

1 Department of Physics, Deshbandhu College, University of Delhi, New Delhi 110019, India 
Publisher's Note Springer Nature remains neutral with regard to jurisdictional claims in published maps and institutional affiliations. 